\title{
CRYSTAL STRUCTURE OF ADIPATE ZINC DIHYDATE
}

\author{
Jian Cai, La-Sheng Long, ${ }^{*}$ and Lan-Sun Zheng*
}

State Key Laboratory for Physical Chemistry of Solid Surface, Department of Chemistry, Xiamen University, Xiamen 361005, China <cjian@yanan.xmu.edu.cn>

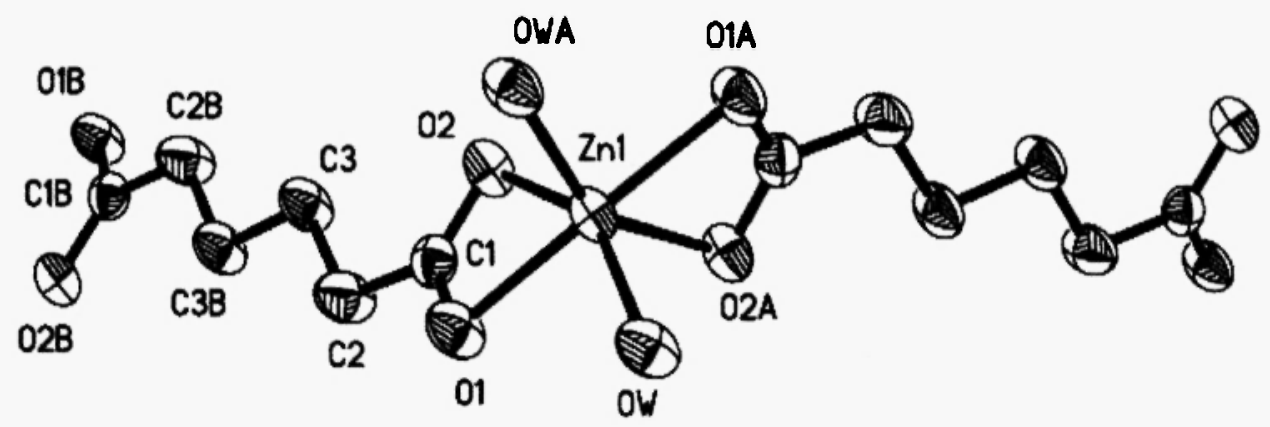

Figure 1. ORTEP plot of a portion of the structure of adipate zinc dihydrate drawn at the $50 \%$ probability level. Selected bond distance and angles: $\mathrm{Znl}-\mathrm{Ow}=2.007(3), \mathrm{ZnI}-\mathrm{Ol}=2.120(3), \mathrm{ZnI}-\mathrm{O} 2=2.246(3)$, Ol$\mathrm{Cl}=1.260(5), \mathrm{O} 2-\mathrm{Cl}=1.248(4) \mathrm{A} ; \mathrm{Ow}-\mathrm{Znl}-\mathrm{Ow} \mathrm{w}^{\mathrm{a}}=100.5(2), \mathrm{Ow}-\mathrm{Znl}-\mathrm{Ol}=90.5(1), \mathrm{Ow}-\mathrm{ZnI}-\mathrm{O} 1=$ 103.0(1), Ol-Znl-Ol ${ }^{\mathrm{a}}=159.0(2), \mathrm{Ow}-\mathrm{Znl}-\mathrm{O} 2=148.7(1), \mathrm{Ow}^{\mathrm{a}}-\mathrm{Znl}-\mathrm{O} 2=95.1(1), \mathrm{O} 1-\mathrm{Znl}-\mathrm{O} 2=59.5(1)$, $\mathrm{O} 1^{\mathrm{a}}-\mathrm{ZnI}-\mathrm{O} 2=103.8(1), \mathrm{O} 2-\mathrm{Zn} 1-\mathrm{O} 2^{\mathrm{a}}=84.9(1)^{\circ}$. Symmetry code: $\mathrm{a}=-x, y, 1 / 2-z$.

\section{Comment}

The two carboxylate groups in adipic acid have been employed as building blocks to form coordination polymers [1-3]. In $\left[\mathrm{Zn}\left(\mathrm{O}_{2} \mathrm{CC}_{4} \mathrm{H}_{8} \mathrm{CO}_{2}\right)\left(\mathrm{H}_{2} \mathrm{O}\right)_{2}\right]_{\mathrm{n}}$, the zinc atom is located on a twofold symmetry axis and is six-coordinated in a distorted octahedral geometry defined by two water molecules and two carboxylate groups derived from two symmetry related bis-bidenate adipate ligands (Figure 1). The adipate ligand acts as a bridging ligand by connecting adjacent two zinc(II) atoms to form an infinite one-dimensional zigzag chain, which, through H-bonding between hydrate oxygens and carboxylate oxygens, are assembled into a two-dimensional structure along $c$-axis (Figure 2). Further $\mathrm{H}$-bonding along the $b$-axis, i.e. between layers, results in the formation of a three-dimensional structure (Figure 3 ). The structure is very similar to the three-dimensional structure formed by zinc(II) and terephthalic acid [4].

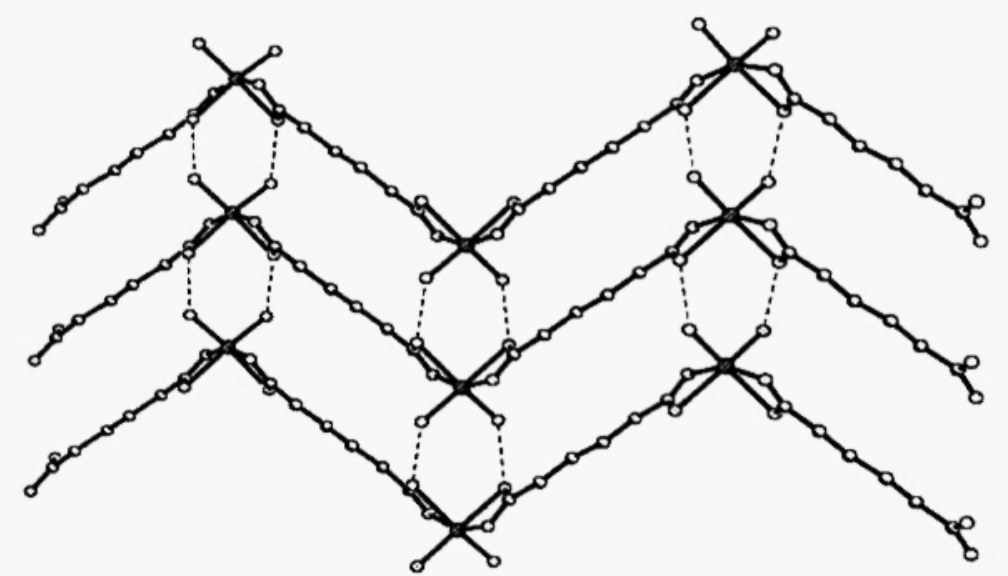

Figure 2. ORTEP plot showing two-dimensional structure in adipate zinc dihydrate connected by $\mathrm{H}$-bonds. viewed along the $c$-axis. 


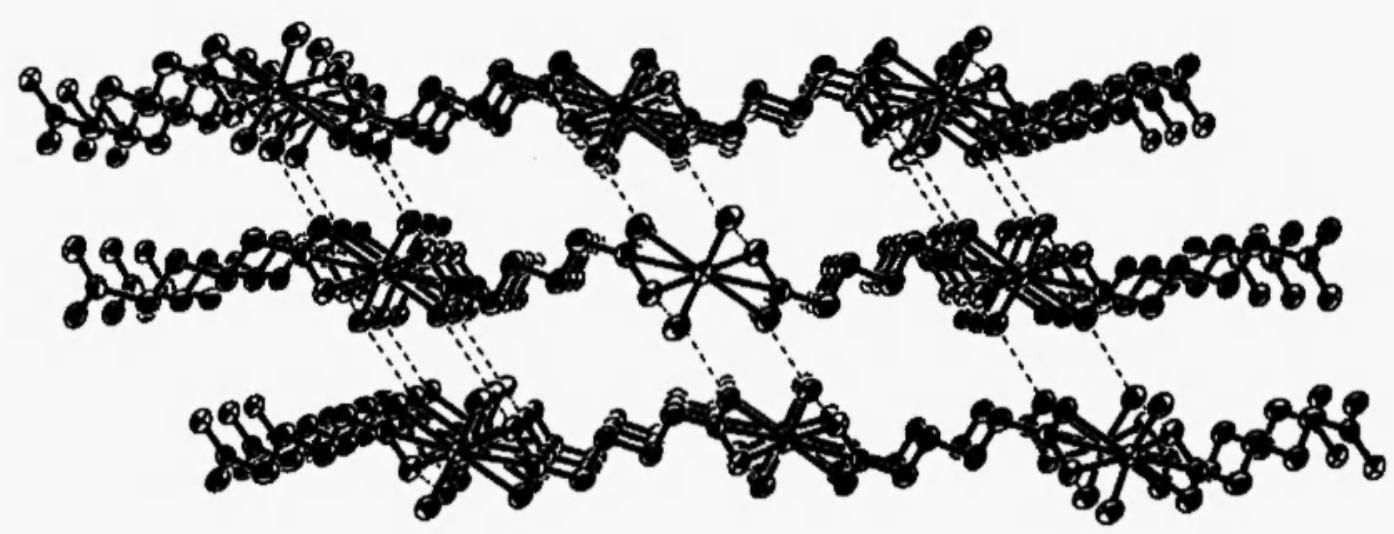

Figure 3. ORTEP plot showing three-dimensional structure of adipate zinc dihydrate connected by $\mathrm{H}$-bonds viewed along the $b$-axis.

\section{Experimental}

Adipic acid $(0.16 \mathrm{~g}, 1.0 \mathrm{mmol})$ was added to a solution of $\mathrm{Zn}\left(\mathrm{NO}_{3}\right)_{2}\left(10 \mathrm{~cm}^{2}\right.$ of $\left.0.4 \mathrm{~mol} \cdot \mathrm{L}^{-1}\right)$. The $\mathrm{pH}$ was adjusted to $5 \sim 6$ by adding $\mathrm{NaOH}$ solution. After most of the acid was dissolved, the mixture was filtered and set aside at room temperature. Colorless single crystals suitable for X-ray diffraction were obtained in a few days.

Table 1. Crystal data for adipate zinc dihydrate complex

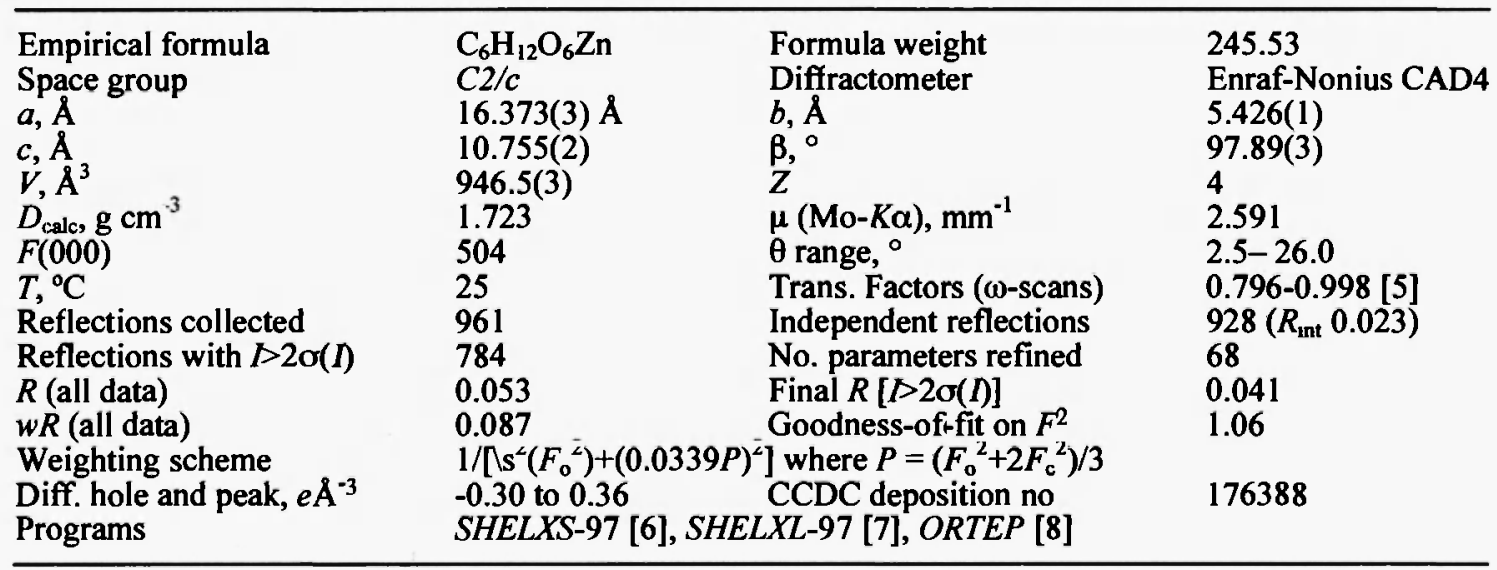

\section{Acknowledgments}

We thank the National Science Foundation of China (Grant no. 29890210) and NSF of Fujian Province, P.R. China (E0110001).

\section{References}

1 E.G. Bakalbassis, M. Korabik, A. Michailides and J. Mrozinski, J. Chem. Soc., Dalton Trans, (2001) 850 .

$2 \quad$ Y. Kim and D.Y. Jung. Inorg. Chem., $39(2000) 1470$.

3 Y.Q. Zheng, J.L. Lin and A.Y. Pan, Z. Anorg. Allg. Chem., 626 (2000) 1718.

$4 \quad$ G. Guilera and J.W. Steed, Chem. Commun., (1999) 1563.

$5 \quad$ A.C.T. North, D.C. Phillips and F.S. Mathews, Acta Cryst., A24 (1968) 351.

6 C.K. Johnson, ORTEP-II. Report ORNL-5138. Oak Ridge National Laboratory, Oak Ridge, Tennessee, USA (1976).

7 G.M. Sheldrick, SHELXS-97. Program for Crystal Structure Solution. University of Gottingen, Germany (1997).

8 G.M. Sheldrick, SHELXL-97. Program for Crystal Structure Refinement. University of Gottingen, Germany (1997). 